\title{
Modifikasi Perencanaan Apartemen Puncak CBD Wiyung dengan Menggunakan Sistem Ganda dan Balok Pratekan pada Lantai Atap
}

\author{
Nadia Jasmine Setianty Simanjuntak, Endah Wahyuni, dan Data Iranata \\ Departemen Teknik Sipil, Fakultas Teknik Sipil, Lingkungan, dan Kebumian, \\ Institut Teknologi Sepuluh Nopember (ITS) \\ e-mail: data@ce.its.ac.id
}

\begin{abstract}
Abstrak-Gedung Apartemen Puncak CBD merupakan hunian vertikal yang terdiri dari 37 lantai untuk unit kamar yang terletak di daerah Wiyung, Surabaya Barat. Apartemen ini dibangun dengan struktur beton bertulang biasa pada keseluruhan lantai dan dilakukan modifikasi pada lantai atap. Modifikasi ini bertujuan untuk mengubah lantai paling atas gedung menjadi suatu ruang serbaguna. Ruang serbaguna didesain memiliki panjang 30 meter dan lebar 13,65 meter dimana kolom-kolom interior ruangan akan dihilangkan dan digantikan fungsinya oleh balok pratekan agar luas ruangan menjadi optimal. Metode beton pratekan yang digunakan dalam modifikasi ini adalah metode post tension (pasca tarik) yang cocok diterapkan pada konstruksi gedung. Perencanaan gedung ini juga menggunakan Sistem Ganda karena apartemen terletak di Kategori Desain Seismik D. Dari hasil Analisa yang telah dilakukan didapatkan kesimpulan bahwa syarat Sistem Ganda terpenuhi, dimana rangka utama gedung mampu menahan beban lateral $X$ dan $Y$ sebesar $29,63 \%$ dan 27,39\%. Gaya pratekan yang dikenakan pada balok pada saat jacking sebesar $1840 \mathrm{kN}$ dengan kehilangan gaya sebesar $19,06 \%$.
\end{abstract}

Kata Kunci-Apartemen Puncak CBD, Balok Pratekan, Pasca Tarik, Sistem Ganda.

\section{PENDAHULUAN}

$\mathrm{S}$ EIRING dengan pertumbuhan jumlah penduduk di kota Surabaya, kebutuhan masyarakat akan hunian tempat tinggal menjadi semakin meningkat. Namun ketersediaan lahan yang ada, berbanding terbalik dengan kebutuhan akan tempat tinggal di Surabaya. Menurut Dinas Kependudukan dan Catatan Sipil, pertumbuhan penduduk untuk kota Surabaya terbilang meningkat tajam yang mencapai 50.000 jiwa tiap tahunnya, khususnya di Surabaya Barat yang jumlah penduduknya mencapai 446.627 jiwa per tahun 2014. Untuk menyiasati keterbatasan lahan tersebut, solusi yang dapat dilakukan adalah pembangunan hunian vertikal seperti gedung apartemen yang mampu menampung penghuni dengan jumlah lebih banyak jika dibandingkan dengan jumlah penghuni dalam suatu perumahan yang dibangun dalam luasan lahan yang sama. Maka dari itulah dilakukan pembangunan gedung apartemen Puncak CBD (Central Business District) yang berlokasi di Kramat Kali, Wiyung, Surabaya Barat.

Pembangunan Apartemen Puncak CBD ini dirancang memiliki ketinggian 37 lantai, 4 lantai parkir, dan 1 lantai atap (roof). Metode yang digunakan dalam pembangunan apartemen ini adalah metode beton konvensional dan metode beton precast. Beton yang digunakan adalah beton bertulang biasa. Beton bertulang mengkombinasikan beton dan tulangan baja dengan cara menyatukan dan membiarkan keduanya bekerja bersama-sama sesuai keinginannya [1].

Selain metode beton bertulang dan precast, masih terdapat metode lain yang dapat diaplikasikan dalam pembangunan suatu gedung. Salah satu metode yang lazim digunakan yakni beton prategang atau pratekan yang merupakan kombinasi ideal dari dua bahan modern. Bahan tersebut adalah baja dan beton berkekuatan tinggi yang dengan cara "aktif" menarik baja dan menahannya ke beton sehingga beton berada dalam keadaan tertekan. Kombinasi aktif ini membuat beton, yang kemampuan terhadap tariknya rendah, diperbaiki dengan cara memberikan tekanan lebih, sementara kemampuan menahan tekanannya tidak dikurangi. Seiring dengan perkembangan historis, pemberian tegangan tidak hanya dilakukan pada beton, namun juga terhadap baja. Pemberian gaya prategang berarti membuat tegangan permanen di dalam struktur dengan tujuan memperbaiki perilaku dan kekuatannya pada bermacam-macam pembebanan [1].

Pemakaian baja dan beton berkekuatan tinggi pada aplikasi balok pratekan menghasilkan batang-batang yang lebih ringan dan lebih langsing daripada beton bertulang. Kelebihannya yang bebas dari retak berpengaruh terhadap peningkatan daya tahan struktur dan kemampuan material untuk menyerap energi pada saat menerima beban. Pemanfaatan beton di dalam daerah tarik pada konsep beton pratekan dapat menghasilkan penghematan beton sebesar 15 sampai 30\% dibandingkan dengan beton bertulang. Meskipun penghematan material tidak berdampak begitu besar dalam penghematan biaya, akibat kebutuhan untuk menghasilkan beton pratekan juga membutuhkan biaya tambahan, namun secara keseluruhan berkurangnya bobot mati akan mengurangi beban rencana dan biaya pondasi [2][3].

Berdasarkan berbagai keuntungan beton pratekan yang telah disebutkan diatas, penulis ingin mengaplikasikan beton pratekan pada modifikasi perencanaan gedung apartemen CBD Wiyung ini. Modifikasi yang dilakukan dengan mempertimbangkan peraturan pembebanan gedung ini pun akan mengubah fungsi lantai ke 37 apartemen Puncak CBD yang semula sebagai unit kamar, dialihfungsikan menjadi ruang serbaguna untuk mengoptimasi kegunaan apartemen yang semula hanya menjadi tempat tinggal, menjadi dapat dimanfaatkan sebagai ruang pertemuan. Ruang serbaguna 
yang dapat digunakan sebagai ruang pertemuan atau ruang jamuan tersebut direncanakan memiliki space yang luas dan nyaman sehingga perlu meminimalisasi adanya kolom bangunan di tengah ruangan. Maka dari itu pada Jurnal ini akan diterapkan aplikasi beton pratekan pada perencanaan balok ruang serbaguna apartemen tersebut, sedangkan perencanaan struktur balok-kolom pada lantai lainnya akan menggunakan metode beton konvensional.

\section{II.TINJAUAN PUSTAKA}

Dalam tinjauan pustaka ini akan dibahas beberapa dasar teori yang berkaitan dengan modifikasi perencanaan apartemen Puncak CBD Wiyung dengan menggunakan sistem ganda dan balok pratekan pada lantai atap. Letak bangunan apartemen yang berada pada zona gempa Surabaya dimana perancangan struktur gedung tahan gempa [4].

Beton pratekan merupakan kombinasi antara beton dengan mutu yang tinggi dan baja dengan mutu yang tinggi dikombinasikan dengan cara aktif. Cara aktif ini dicapai dengan cara menarik baja dengan menahannya ke beton sehingga beton dalam keadaan tertekan. Karena penampang beton sebelum beban bekerja telah dalam kondisi tertekan, maka bila beban bekerja, tegangan tarik yang terjadi dapat dieliminasi oleh tegangan tekan yang telah diberikan pada penampang sebelum beban bekerja.

Beton pratekan dapat didefinisikan sebagai beton yang diberikan tegangan internal sebelum dikenakan beban. Ada 3 konsep yang digunakan untuk menganalisa sifat-sifat dasar beton pratekan [5]:

1. Sistem pratekan untuk mengubah beton yang getas menjadi bahan yang elastis.

2. Sistem pratekan untuk kombinasi baja mutu tinggi dengan beton mutu tingg.

3. Sistem Pratekan untuk mencapai keseimbangan beban.

Metode yang digunakan dalam pengerjaan jurnal ini adalah metode pasca tarik. Pada metode pascatarik, beton dicor terlebih dahulu, dimana sebelumnya telah disiapkan saluran kabel atau tendon yang disebut duct.

Berikut merupakan tahap pelaksanaan sistem pratekan pasca tarik yang diilustrasikan pada Gambar 1:

Tahap 1: Dengan cetakan (formwork) yang telah disediakan lengkap dengan saluran/selongsong kabel pratekan (tendon duct) yang dipasang melengkung sesuai dengan bidang momen balok, beton dicor.

Tahap 2: Setelah beton cukup umur dan kuat memikul gaya pratekan, tendon atau kabel pratekan dimasukkan dalam selongsong (tendon duct), kemudian ditarik untuk mendapatkan gaya pratekan.

Tahap 3: Setelah diangkur, balok beton menjadi tertekan, gaya pratekan telah ditransfer ke beton. Karena tendon dipasang melengkung, maka akibat gaya pratekan tendon memberikan beban merata ke balok yang arahnya keatas, akibatnya balok melengkung keatas.

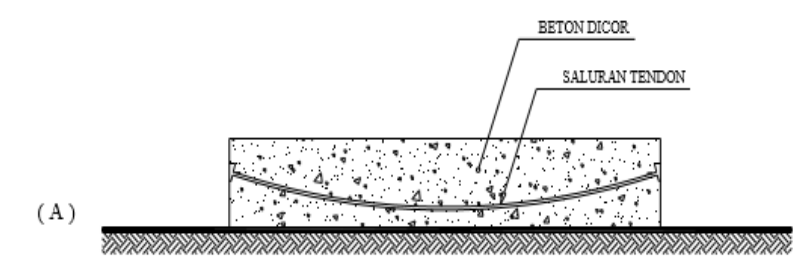

(B)

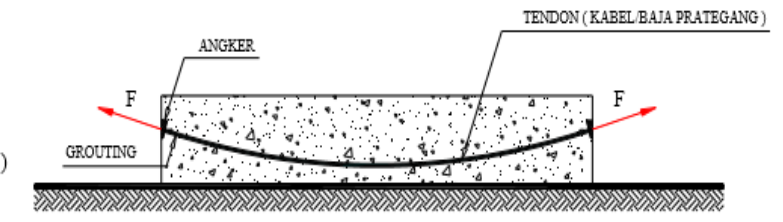

(C)

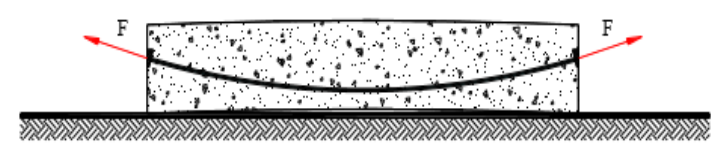

Gambar 1. Metode Pelaksanaan Pasca Tarik [3].

\section{METODOLOGI}

Tahapan dalam pengerjaan jurnal ini menurut urutan pelaksanaannya dapat dilihat melalui diagram alir pada Gambar 2. Data bangunan yang akan digunakan dalam pengerjaan Jurnal yaitu data gedung Apartemen Puncak CBD Wiyung.

\section{Data Gedung Sebelum dimodifikasi:}

Tipe Bangunan : Gedung Apartemen

Lokasi : Jalan Kramat Kali Wiyung, Surabaya

Barat

Ketinggian Lantai

- Basement (B1) : :3,5 m

- Lobby :4,0 m

- Lantai Parkir 1-4 : $13,15 \mathrm{~m}$

- Lantai 1-37 : 109,6 m

Tinggi Total Bangunan: 126,75 m

Mutu Beton (fc') : $40 \mathrm{MPa}$

Mutu Baja (fy) : $400 \mathrm{Mpa}$

Data Gedung Setelah di modifikasi :

Tipe Bangunan : Gedung Apartemen

Lokasi : Jalan Kramat Kali Wiyung, Surabaya

Barat

Ketinggian Lantai

- Lobby : :3,0 m

- Lantai Parkir 1-4 :9 m

- Lantai 1-37 : 109,6 m

Tinggi Total Bangunan: 121,65 m

Mutu Beton (fc') : $40 \mathrm{MPa}$

Mutu Baja (fy) $\quad: 400 \mathrm{MPa}$ 


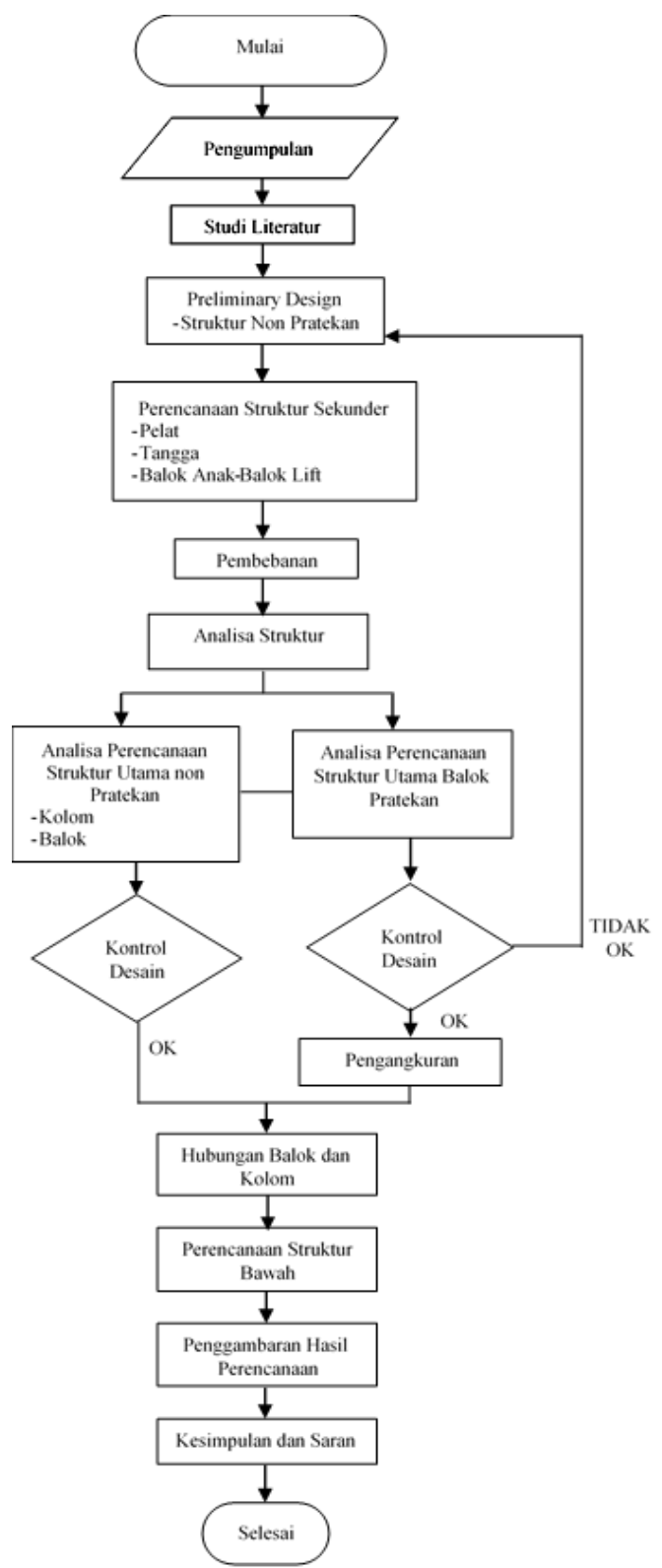

Gambar 2. Diagram alir penyelesaian jurnal.

\section{HASIL DAN PEMBAHASAN}

\section{A. Preliminary Design}

Perencanaan awal dilakukan menurut peraturan structural untuk bangunan gedung yang ada [6][7]. Preliminary desain yang dilakukan terhadap komponen struktur antara lain balok induk, balok anak, balok pratekan, pelat, dan kolom. Sebelum melakukan preliminary, sebaiknya dilakukan penentuan data perencanaan dan beban yang akan diterima oleh struktur gedung.

Tabel 1.

Rekapitulasi Perencanaan Dimensi Balok Anak

\begin{tabular}{cccccc}
\hline \hline Nama Balok & Bentang & $\mathrm{h}_{\min }$ & $\mathrm{b}_{\min }$ & \multicolumn{2}{c}{ Dimensi } \\
\hline & $(\mathrm{mm})$ & $(\mathrm{mm})$ & $(\mathrm{m})$ & $\mathrm{h}(\mathrm{mm})$ & $\mathrm{b}(\mathrm{mm})$ \\
\hline B1 & 5000 & 303,6 & 202,4 & 500 & 300 \\
B2 & 4800 & 291,4 & 194,3 & 500 & 300 \\
B3 & 4425 & 268,7 & 179,1 & 500 & 300 \\
B4 & 3000 & 182,1 & 121,4 & 350 & 250 \\
B5 & 2400 & 145,7 & 97,1 & 350 & 250 \\
\hline \hline
\end{tabular}

Tabel 2.

Rekapitulasi Dimensi Balok Anak

\begin{tabular}{cccccc}
\hline \hline Nama Balok & Bentang $(\mathrm{mm})$ & $\mathrm{hmin}$ & bmin & \multicolumn{2}{c}{ Dimensi } \\
& & $(\mathrm{mm})$ & $(\mathrm{mm})$ & $\mathrm{h}(\mathrm{mm})$ & $\mathrm{b}(\mathrm{mm})$ \\
BA1 & 5000 & 231,3 & 154,2 & 300 & 250 \\
\hline \hline
\end{tabular}

Tabel 3.

Rekapitulasi Dimensi Pelat Lantai dan Atap

\begin{tabular}{cccccc}
\hline \hline Tipe Pelat & $\begin{array}{c}\text { Ukuran } \\
(\mathrm{cm})\end{array}$ & Tipe Arah & $\begin{array}{c}\text { Tebal min } \\
(\mathrm{cm})\end{array}$ & \multicolumn{2}{c}{ Tebal Pakai $(\mathrm{cm})$} \\
1 & $500 \times 442,5$ & 2 & 11,03 & 13 & 12 \\
2 & $500 \times 480$ & 2 & 11,24 & 13 & 12 \\
3 & $442,5 \times 270$ & 2 & 8,76 & 13 & 12 \\
4 & $442,5 \times 442,5$ & 2 & 9,95 & 13 & 12 \\
5 & $442,5 \times 480$ & 2 & 10,66 & 13 & 12 \\
6 & $480 \times 480$ & 2 & 10,86 & 13 & 12 \\
7 & $442,5 \times 240$ & 2 & 6,25 & 13 & 12 \\
8 & $442,5 \times 500$ & 2 & 11,27 & - & 12 \\
\hline \hline
\end{tabular}

Rekapitulasi dimensi kolom yang digunakan:

- Kolom 28- Lt. Atap : 60/60 cm

- Kolom Lt. 18 - 27 : 65/65 cm

- Kolom Lt. 8 - $17 \quad: 75 / 75 \mathrm{~cm}$

- Kolom Lobby - Lt.7: 85/85 cm

Rekapitulasi Balok Prategang

Bentang : :13,65 m

Dimensi balok: $50 / 70 \mathrm{~cm}$

\section{B. Perencanaan Struktur Sekunder}

1. Perencanaan Tangga
- Tinggi lantai
$: 295 \mathrm{~cm}$
- Lebar Tangga
: $120 \mathrm{~cm}$
- Panjang Tangga
: $300 \mathrm{~cm}$
- Elevasi Bordes
$: 147,5 \mathrm{~cm}$
- Lebar Bordes
$: 140 \mathrm{~cm}$
- Panjang Bordes
$: 270 \mathrm{~cm}$
- Tebal Bordes
$: 15 \mathrm{~cm}$
- Jumlah Tanjakan
: 20 buah
- Jumlah injakan
: 19 buah
- Lebar Injakan (i)
: 30 buah
- Tinggi injakan (t)
$: 15 \mathrm{~cm}$
- Tebal pelat tangga (tp)
$: 15 \mathrm{~cm}$
- Selimut beton
$: 2 \mathrm{~cm}$
- Mutu beton (fc')
: $30 \mathrm{MPa}$
- Mutu baja (fy)
: $400 \mathrm{MPa}$

Tabel 4.

Rekapitulasi Penulangan Tangga

\begin{tabular}{ccccc}
\hline \hline \multicolumn{5}{c}{ Tangga Tipe 1 $(\mathrm{h}=2950 \mathrm{~mm})$} \\
\hline Nama struktur & \multicolumn{4}{c}{ Tulangan } \\
& Lentur & Bagi & Susut \\
Pelat Tangga tipe 1 & D13-110 & D10-250 & D10-250 \\
Pelat Bordes & D13-125 & D10-330 & D10-115 \\
Nama struktur & Lentur & \multicolumn{2}{c}{ Geser } \\
& Lapangan & Tumpuan & Lapangan & Tumpuan \\
Balok Bordes & 2D13 & 1D13 & D10-150 & D10-100 \\
& Tangga tipe 2 $(\mathrm{h}=3000 \mathrm{~mm})$ & \\
Nama struktur & \multicolumn{4}{c}{ Tulangan } \\
Lentur & Bagi & Susut \\
Pelat Tangga tipe 2 & D13-115 & D10-300 & D10-250 \\
Pelat Bordes & D13-125 & D10-330 & D10-115 \\
Nama struktur & \multicolumn{2}{c}{ Lentur } & Geser \\
& Lapangan Tumpuan & Lapangan & Tumpuan \\
Balok Bordes & 2D13 & 1D13 & D10-150 & D10-100
\end{tabular}




\begin{tabular}{ccccc}
\multicolumn{5}{c}{ Tangga tipe 3 $(\mathrm{h}=3400 \mathrm{~mm})$} \\
Nama struktur & Lentur & Tulangan \\
Pelat Tangga tipe 3 & D13-115 & Bagi & Susut \\
Pelat Bordes & \multicolumn{2}{c}{ D13-125 } & D10-330 & D10-250 \\
Nama struktur & \multicolumn{2}{c}{ Lentur } & \multicolumn{2}{c}{ Geser } \\
& Lapangan & Tumpuan & Lapangan & Tumpuan \\
Balok Bordes & 2D13 & 1D13 & D10-150 & D10-100 \\
\hline \hline
\end{tabular}

2. Perencanaan Pelat

Pelat direncanakan dibagi menjadi pelat lantai dan pelat atap. Ketebalan pelat direncanakan yaitu $13 \mathrm{~cm}$ dan $12 \mathrm{~cm}$.

Tabel 5

\begin{tabular}{|c|c|c|c|c|}
\hline \multicolumn{5}{|c|}{ Pelat Lantai Apartemen } \\
\hline \multirow{2}{*}{ Tipe } & \multirow[t]{2}{*}{ Arah } & \multirow{2}{*}{$\begin{array}{l}\mathrm{h} \text { pelat } \\
(\mathrm{cm})\end{array}$} & \multicolumn{2}{|c|}{ Tulangan } \\
\hline & & & $X$ & $\mathrm{Y}$ \\
\hline 1 & 2 & 13 & D10-200 & D10-200 \\
\hline 2 & 2 & 13 & D10-250 & D10-250 \\
\hline 3 & 2 & 13 & D10-250 & D10-250 \\
\hline 4 & 2 & 13 & D10-250 & D10-250 \\
\hline 5 & 2 & 13 & D10-250 & D10-250 \\
\hline 6 & 2 & 13 & D10-250 & D10-250 \\
\hline 7 & 2 & 13 & D10-250 & D10-250 \\
\hline \multicolumn{5}{|c|}{ Pelat Lantai Atap } \\
\hline \multirow[t]{2}{*}{ Tipe } & \multirow[t]{2}{*}{ Arah } & $\mathrm{h}$ pelat & \multicolumn{2}{|c|}{ Tulangan } \\
\hline & & $(\mathrm{cm})$ & $\mathrm{X}$ & $\mathrm{Y}$ \\
\hline $1 \mathrm{~A}$ & 2 & 12 & D10-200 & D10-200 \\
\hline $2 \mathrm{~A}$ & 2 & 12 & D10-200 & D10-200 \\
\hline $3 \mathrm{~A}$ & 2 & 12 & D10-250 & D10-250 \\
\hline $4 \mathrm{~A}$ & 2 & 12 & D10-250 & D10-250 \\
\hline $5 \mathrm{~A}$ & 2 & 12 & D10-200 & D10-250 \\
\hline $6 \mathrm{~A}$ & 2 & 12 & D10-200 & D10-200 \\
\hline $7 \mathrm{~A}$ & 2 & 12 & D10-250 & D10-250 \\
\hline $8 \mathrm{~A}$ & 2 & 12 & D10-200 & D10-200 \\
\hline
\end{tabular}

3. Perencanaan Balok Anak

Balok anak merupakan struktur sekunder yang berfungsi sebagai pembagi pendistrib usi beban.

Tabel 6.

Rekapitulasi Penulangan Balok Anak

\begin{tabular}{cccccc}
\hline \hline \multicolumn{5}{c}{ Balok Anak Ballroom } \\
\hline Tipe & \multicolumn{2}{c}{ Tumpuan } & \multicolumn{2}{c}{ Lapangan } & Sengkang \\
\cline { 2 - 5 } Balok & Negatif & Positif & Negatif & Positif & \\
\hline BA1 & 2D16 & 2D16 & 2D16 & 2D16 & 2D10-120 \\
\hline \hline
\end{tabular}

4. Perencanaan Balok Lift

Pada bangunan ini menggunakan lift penumpang dengan data sebagai berikut (untuk lebih jelasnya dapat lihat di lampiran brosur lift):

$\begin{array}{ll}\text { Tipe lift } & : \text { Passanger Elevator } \\ \text { Merk } & : \text { Hyundai } \\ \text { Kapasitas } & : 1814 \mathrm{~kg} \\ \text { Lebar pintu (opening width) } & : 1219 \mathrm{~mm} \\ \text { Dimensi ruang luncur } & : 3137 \mathrm{~mm} \times 2032 \mathrm{~mm} \\ \text { Dimensi sangkar } & \\ \text { Internal } & : 2337 \mathrm{~mm} \times 1651 \mathrm{~mm} \\ \text { Dimensi ruang mesin }(1 \mathrm{car}) & : 3442 \mathrm{~mm} \times 3556 \mathrm{~mm} \\ \text { Beban reaksi ruang mesin } & \\ \text { R1 } & : 73 \mathrm{kN} \\ \text { R2 } & : 138 \mathrm{kN}\end{array}$

Dimensi balok penumpu Lift yaitu $300 \times 500 \mathrm{~mm}$. C.Analisa Struktur
Dalam perhitungan analisis beban gempa perlu suatu permodelan struktur, dimana struktur Apartemen Puncak CBD Wiyung memiliki bentuk yang tidak beraturan, sehingga harus dilakukan analisa terhadap gedung dengan menggunakan analisa respon dinamik [4][8], dan [9].

1. Kontrol Pembebanan

Total perbedaan berat struktur perhitungan manual dan etabs, adalah $1,9 \%<5 \%(\mathbf{O K})$

2. Kontrol Getar Waktu Alami

$\mathrm{T}$ terbesar yang didapat dari analisis $\mathrm{ETABS}=3,457 \mathrm{~s}$, maka:

$$
\begin{array}{ll}
-\mathrm{T}<\mathrm{Cu} \times \mathrm{Ta} & -\mathrm{T} \quad<\mathrm{Ta} \\
3,457 \mathrm{~s}<4,914 \mathrm{~s}(\mathbf{O K}) & 3,457 \mathrm{~s}<3,506 \mathrm{~s}(\mathbf{O K})
\end{array}
$$

3. Kontrol Base Shear

Jika kombinasi respons untuk geser dasar ragam (Vt) lebih kecil 85 persen dari geser dasar yang dihitung (V) menggunakan prosedur gaya lateral ekivalen, maka gaya harus dikalikan dengan 0,85×V/Vt (SNI 1726:2012 Pasal 7.9.4.1). $\mathrm{R}$ untuk sistem ganda dengan Rangka Beton Bertulang Pemikul Momen Khusus dan Dinding Geser Beton Bertulang Khusus adalah 7.

$$
\begin{aligned}
& \mathrm{Vxt}>0,85 \mathrm{~V} ; 8169,7 \mathrm{kN}>7851,787 \mathrm{kN} \quad(\mathbf{O K}) \\
& \mathrm{Vyt}>0,85 \mathrm{~V} ; 8328,82 \mathrm{kN}>7851,787 \mathrm{kN}(\mathbf{O K})
\end{aligned}
$$

4. Kontrol Dual System

Sistem Rangka Pemikul Momen (SRPM) harus memikul minimum $25 \%$ dari beban geser nominal total yang bekerja dalam arah kerja beban gempa tersebut.

Tabel 7.

Kontrol Sistem Ganda

\begin{tabular}{lcccc}
\hline \hline & $\begin{array}{c}\text { Gempa X } \\
(\mathrm{kN})\end{array}$ & $\begin{array}{c}\text { Gempa Y } \\
(\mathrm{kN})\end{array}$ & \% Gempa X & \% Gempa Y \\
\hline SRPM & 2857,33 & 3202,10 & $\mathbf{2 9 , 6 3}$ & $\mathbf{2 7 , 3 9}$ \\
Shearwall & 6784,99 & 8488,15 & 70,37 & 72,61 \\
Total & 9642,32 & 11690,25 & 100,00 & 100,00 \\
\hline \hline
\end{tabular}

\section{Kontrol Partisipasi massa}

Berdasarkan hasil analisis perhitungan pada program bantu ETABS, partisipasi massa menghasilkan respon $90 \%$ pada mode ke 11. (OK)

6. Kontrol Drift

Berikut merupakan drift ijin yang didapat dari perhitungan

Drift maks arah gempa Y : 8,36 m $<59 \mathrm{~mm} \quad$ (OK)

Drift maks arah gempa X : 10,565 mm $<59 \mathrm{~mm}(\mathbf{O K})$

D.Perencanaan Struktur Utama Pratekan

Perencanaan dimensi balok pratekan yang digunakan untuk menggantikan fungsi kolom pada lantai atap (ruang serbaguna) sesuai dengan ketentuan yang berlaku [6][10], dan [11].

- Dimensi : 50/70 cm

- Panjang : 13,65 m

- Koordinat tendon

Tumpuan : $+10 \mathrm{~cm}$ dari c.g.c

Lapangan: +10 dari titik terbawah balok

- Fo pakai : $1840 \mathrm{kN}$

- Fe : 1489,35 kN 


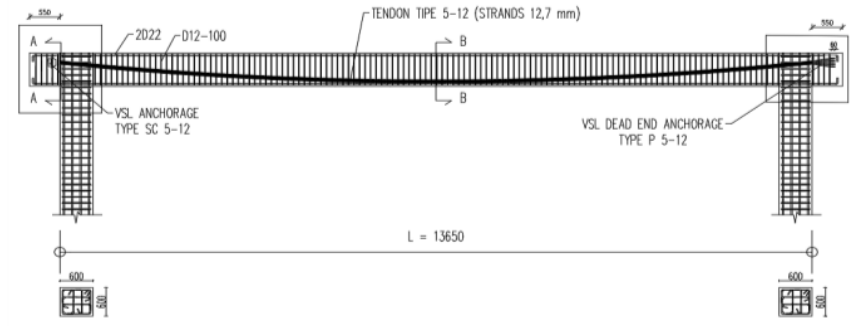

Gambar 3. Potongan memanjang balok pratekan.

1. Kehilangan gaya prategang

Total kehilangan prategang secara langsung dan tidak langsung yaitu sebesar 19,0568\%.

Tabel 8.

Rekapitulasi Kehilangan Prategang

\begin{tabular}{lll}
\hline $\begin{array}{c}\text { Kehilangan Gaya } \\
\text { Prategang }\end{array}$ & \multicolumn{1}{c}{ Akibat } & \multicolumn{1}{c}{$\begin{array}{c}\text { Presentase } \\
\text { kehilangan (\%) }\end{array}$} \\
\hline Langsung & Slip angker & 5,586 \\
\cline { 2 - 3 } & Perpendekan elastis & - \\
\cline { 2 - 3 } & Wobble effect & 0,1528 \\
\cline { 2 - 3 } & Kekekangan Kolom & 3,5065 \\
\hline $\begin{array}{l}\text { Tidak Langsung } \\
\text { (Waktu) }\end{array}$ & Susut & 0,0288 \\
\cline { 2 - 3 } & Relaksasi Baja & 9,788 \\
\hline
\end{tabular}

2. Rekapitulasi perencanaan strutur pratekan

Momen nominal tumpuan di tendon: 244,085 kN.m

Momen nominal tumpuan lunak $\quad: 301,358 \mathrm{kN} . \mathrm{m}$

Momen nominal total

Mu tumpuan

Momen nominal lapangan

Mu lapangan

Fpc : 545,444 kN.m : 436,714 kN.m

: $1271,98 \mathrm{kN} . \mathrm{m}$

: 345,772 kN.m

Lendutan saat jacking

Lendutan setelah transfer

Tulangan lentur di tumpuan

Tulangan susut di tumpuan

: 3,441 MPa

$: 10,356 \mathrm{~mm}$

: $-17,232 \mathrm{~mm}$

$: 4 \mathrm{D} 22$

: 4D22

: D12-100

Tulangan geser

: Tidak diperlukan

Tulangan torsi

\section{E. Perencanaan Struktur Utama Non Pratekan}

Perencanaan struktur utama non pratekan ini meliputi perencanaan balok induk, kolom, hubungan balok kolom, shearwall [6][12], dan [13].

Tabel 9.

Rekapitulasi Penulangan Lentur Balok Induk Lantai

\begin{tabular}{ccccc}
\hline \hline \multicolumn{4}{c}{ Balok Induk Lantai Apartemen } \\
\hline Tipe Balok & \multicolumn{2}{c}{ Tumpuan } & \multicolumn{2}{c}{ Lapangan } \\
\cline { 2 - 5 } & Negatif & Positif & Negatif & Positif \\
B1 & 3D16 & 4D16 & 3D16 & 3D16 \\
B2 & 3D16 & 4D16 & 3D16 & 3D16 \\
B3 & 3D16 & 6D16 & 3D16 & 4D16 \\
B4 & 2D16 & 2D16 & 3D16 & 6D16 \\
B5 & 4D16 & 4D16 & 2D16 & 3D16 \\
\hline \hline
\end{tabular}

Tabel 10.

Rekapitulasi Penulangan Lentur Balok Induk Atap

\begin{tabular}{ccccc}
\hline \hline \multicolumn{5}{c}{ Balok Induk Atap } \\
\hline Tipe Balok & Tumpuan & Lapangan & & \\
\cline { 2 - 5 } & Negatif & Positif & Negatif & Positif \\
B1 & 3D16 & 3D16 & 3D16 & 3D16 \\
B2 & 3D16 & 3D16 & 3D16 & 3D16 \\
B3 & 3D16 & 5D16 & 3D16 & 3D16 \\
B4 & 2D16 & 2D16 & 2D16 & 2D16 \\
B5 & 2D16 & 3D16 & 2D16 & 2D16 \\
\hline \hline
\end{tabular}

Tabel 11.

Rekapitulasi Penulangan Longitudinal Penahan Torsi

\begin{tabular}{cccccc}
\hline \hline \multicolumn{5}{c}{ Balok Induk Apartemen } \\
\hline Tipe Balok & Atas & Bawah & Kiri & Kanan & Total \\
\hline B1 & D16 & D16 & D16 & D16 & 4D16 \\
B2 & D16 & D16 & D13 & D13 & 2D16-2D13 \\
B3 & D16 & D16 & D16 & D16 & 4D16 \\
B4 & - & - & D16 & D16 & 2D16 \\
B5 & - & - & D16 & D16 & 2D16 \\
\multicolumn{5}{c}{ Balok Induk Atap } \\
Tipe Balok & Atas & Bawah & Kiri & Kanan & Total \\
B1 & D16 & D16 & D16 & D16 & 4D16 \\
B2 & D16 & - & D16 & D16 & 3D16 \\
B3 & D16 & - & D13 & D13 & 3D16 \\
B4 & - & - & D16 & D16 & 2D16 \\
B5 & - & - & D16 & D16 & 2D16 \\
\hline \hline
\end{tabular}

Tabel 12.

Rekapitulasi Penulangan Geser Balok Induk

\begin{tabular}{|c|c|c|c|}
\hline \multicolumn{4}{|c|}{ Balok Induk Apartemen } \\
\hline $\begin{array}{c}\text { Tipe } \\
\text { Balok }\end{array}$ & $\begin{array}{l}\text { Daerah sendi plastis } \\
\qquad(<2 \mathrm{~h})\end{array}$ & $\begin{array}{l}\text { Di luar sendi plastis } \\
(>2 \mathrm{~h})\end{array}$ & $2 \mathrm{~h}(\mathrm{~mm})$ \\
\hline B1 & D10-70 & D10-120 & 1000 \\
\hline B2 & D10-90 & D10-130 & 1000 \\
\hline B3 & 2D10-90 & 2D10-180 & 1000 \\
\hline B4 & D10-60 & D10-140 & 700 \\
\hline B5 & D10-40 & D10-100 & 700 \\
\hline \multicolumn{4}{|c|}{ Balok Induk Atap } \\
\hline $\begin{array}{l}\text { Tipe } \\
\text { Balok }\end{array}$ & $\begin{array}{c}\text { Daerah sendi plastis } \\
(<2 \mathrm{~h})\end{array}$ & $\begin{array}{l}\text { Di luar sendi plastis } \\
(>2 \mathrm{~h})\end{array}$ & $2 \mathrm{~h}(\mathrm{~mm})$ \\
\hline B1 & D10-80 & D10-120 & 1000 \\
\hline B2 & D10-90 & D10-170 & 1000 \\
\hline B3 & D10-70 & D10-140 & 1000 \\
\hline B4 & D10-60 & D10-140 & 700 \\
\hline B5 & D10-70 & D10-140 & 700 \\
\hline
\end{tabular}

Tabel 13.

Rekapitulasi Penulangan Kolom

\begin{tabular}{|c|c|c|c|c|c|}
\hline \multirow[t]{2}{*}{ Tipe } & \multirow{2}{*}{$\begin{array}{c}\text { Tulangan } \\
\text { Longitu } \\
\text { dinal }\end{array}$} & \multicolumn{2}{|c|}{ Tulangan Transversal } & \multirow{2}{*}{$\begin{array}{l}\text { Tula } \\
\text { ngan } \\
\text { Torsi }\end{array}$} & \multirow{2}{*}{$\begin{array}{c}\text { Panjang } \\
\text { Sambungan } \\
\text { Lewatan } \\
(\mathrm{mm})\end{array}$} \\
\hline & & $\begin{array}{l}\text { Sendi } \\
\text { Plastis }\end{array}$ & $\begin{array}{l}\text { Non Sendi } \\
\text { Plastis }\end{array}$ & & \\
\hline Kolom $85 / 85$ & 12D29 & 5D16-125 & 5D16-150 & - & 900 \\
\hline Kolom 75/75 & $12 \mathrm{D} 29$ & 5D16-130 & 5D16-150 & - & 900 \\
\hline Kolom 65/65 & $12 \mathrm{D} 29$ & 5D16-130 & 5D16-150 & - & 900 \\
\hline Kolom 60/60 & $8 \mathrm{D} 25$ & 4D19-130 & 4D19-150 & - & 750 \\
\hline
\end{tabular}

Tabel 14.

Rekapitulasi Perencanaan Shearwall

\begin{tabular}{cccc}
\hline \hline Tipe & $\begin{array}{c}\text { Tulangan } \\
\text { Geser Vertikal }\end{array}$ & $\begin{array}{c}\text { Tulangan Geser } \\
\text { Horizontal }\end{array}$ & $\begin{array}{c}\text { Panjang Boundry } \\
\text { Element }\end{array}$ \\
\hline Arah X & D25-150 & D19-100 & 1600 \\
Arah Y & D25-150 & D19-100 & 1100 \\
\hline \hline
\end{tabular}

5. Perencanaan Pondasi

Perencanaan pondasi gedung ini, menggunakan digunakan pondasi dalam yaitu tiang pancang tipe Prestressed Concrete Spun Piles produk dari PT. Wijaya Karya Beton [14].

1. Tiang pancang beton pracetak dengan penampang bulat.

2. Mutu beton tiang pancang, $\mathrm{fc}^{\prime}=52 \mathrm{MPa}$. (concrete cube compressive strength is $600 \mathrm{~kg} / \mathrm{cm}^{2}$ at 28 days)

Spesifikasi tiang pancang
Diameter tiang
: $600 \mathrm{~mm}$
Klasifikasi
: $\mathrm{C}$
Concrete cross section $: 1570 \mathrm{~cm}^{3}$
Berat
: $393 \mathrm{~kg} / \mathrm{m}$
Bending momen ultimate: 58 t.m 
Bending momen crack $: 29$ t.m

Allowable axial load $\quad: 229,5$ ton

\section{V.KESIMPULAN}

\section{A. Kesimpulan}

Berdasarkan hasil analisis yang telah dilakukan secara keseluruhan dalam Modifikasi Perencanaan Apartemen Puncak CBD Wiyung dengan Menggunakan Sistem Ganda dan Balok Pratekan pada Lantai Atap, didapatkan beberapa kesimpulan:

1. Perencanaan Apartemen Puncak CBD Wiyung memiliki dimensi struktur baik struktur sekunder dan struktur utama sebagai berikut:

\section{Struktur Sekunder}

- Balok Anak : 25/30 cm

- Balok Bordes : 15/20 cm

- Balok Lift $\quad: 30 / 50 \mathrm{~cm}$

- Tebal Pelat

Pelat Lantai : $13 \mathrm{~cm}$

Pelat Atap : $12 \mathrm{~cm}$

- Dinding Geser

Arah X dan Y: $400 \mathrm{~mm}$

\section{Struktur Utama}

- Balok Induk

$$
\begin{array}{ll}
\text { B1-B3 } & : 30 / 50 \mathrm{~cm} \\
\text { B4 } & : 25 / 35 \mathrm{~cm} \\
\text { B5 } & : 25 / 35 \mathrm{~cm}
\end{array}
$$

- Balok Pratekan : 50/70 cm

- Kolom

$$
\begin{array}{ll}
\text { Lantai Lobby - Lt.7 }: 85 / 85 \mathrm{~cm} \\
\text { Lantai 8-17 } & : 75 / 75 \mathrm{~cm} \\
\text { Lantai } 18-27 & : 65 / 65 \mathrm{~cm} \\
\text { Lantai 28-37 } & : 60 / 60 \mathrm{~cm}
\end{array}
$$

- Pondasi : terdiri dari 7 tipe, yaitu 6 tiang, 4 tiang, 24 tiang, 70 tiang, 51 tiang, dan 10 tiang.

- Tiang Pancang: Spun Pile $600 \mathrm{~mm}$.

2. Hasil perhitungan gaya gempa menggunakan analisa respon spectrum menunjukkan bahwa Apartemen Puncak CBD Wiyung termasuk ke dalam kategori desain seismik D.

3. Hasil analisa struktur apartemen telah memenuhi kontrol pembebanan, kontrol sistem ganda, kontrol drift, kontrol geser dasar, dan kontrol periode getar alami.

4. Hasil gaya pratekan yang terjadi pada struktur primer balok pratekan adalah sejumlah $1840 \mathrm{kN}$, dengan kehilangan gaya pratekan sebesar $19,06 \%$.

5. Perhitungan pada struktur pondasi telah memenuhi persyaratan dimensi dan kontrol geser pons akibat kolom maupun tiang pancang.

\section{B. Saran}

Saran yang dapat diberikan berdasarkan hasil analisa dalam Jurnal ini diantaranya:

1. Perencanaan dimensi balok pratekan harus didesain seefektif mungkin, sehingga kehilangan gaya prategang yang terjadi dapat diminimalisasi.

2. Penempatan shearwall pada gedung harus diperhatikan agar tidak mengurangi nilai fungsi suatu ruang dan tetap memenuhi persyaratan akibat gempa.

3. Setiap perencanaan harus memperhitungkan metode pelaksanaan yang sesuai, agar dapat dilaksanakan dengan baik di lapangan.

4. Studi mengenai perencanaan dan pelaksanaan metode beton pratekan pada gedung perlu ditingkatkan dengan tetap mempertimbangkan berbagai aspek dalam dunia kontruksi.

\section{DAFTAR PUSTAKA}

[1] Lyn and Burns., Design of Prestressed Concrete Structures. USA: John Wiley \& Sons Inc, 1999.

[2] R. Krisna, Prestressed Concrete. New Delhi: McGraw-Hill Company Limited, 1981.

[3] E. G. Nawy, Prestressed Concrete. USA: Prentice Hal, Inc, 2000.

[4] Badan Standarisasi Nasional, "Tata Cara Perencanaan Ketahanan Gempa Untuk Bangunan Gedung (SNI 03-1726-2012)," Bandung, 2012.

[5] Soetoyo, "Diktat Konstruksi Beton Pratekan," Jakarta, 2014.

[6] Badan Standardisasi Nasional, "Persyaratan beton struktural untuk bangunan gedung (SNI 2847:2013)," Jakarta, 2013.

[7] Badan Standarisasi Nasional, "SNI 1727:2013 Beban Minimum Untuk Perancangan Bangunan Gedung dan Struktur Lain," Jakarta, 2013.

[8] Tavio and B. Kusuma, Desain Sistem Rangka Pemikul Momen dan Dinding Struktur Beton Bertulang Tahan Gempa. Surabaya: ITS Press, 2009.

[9] E. Wahyuni, P. Aji, D. Iranata, and F. Budiman, "Study of Rapid Visual Screening of Buildings for High Potential Seismic Hazard According to Indonesian Standard," IPTEK J. Proc. Ser., vol. 3, no. 2, 2017.

[10] Precast/Prestressed Concrete Institute, PCI Design Handbook Precast and Prestressed Concrete. Chicago: PCI Industry Handbook Committee, 2004.

[11] N. Ilham, Perhitungan Balok Prategang Jembatan Srandakan Kulon Progo. Yogyakarta: MNI-EC, 2008.

[12] American Association State Highway and Transportation Officials, "Standard Specification for Deformed and Plain Carbon-Steel Bars for Concrete Reinforcement," America, 2016.

[13] R. Purwono, Perencanaan Struktur Beton Bertulang Tahan Gempa. Surabaya: ITS Press, 2005.

[14] H. Wahyudi, Daya Dukung Pondasi Dalam. Surabaya: Jurusan Teknik Sipil FTSP - ITS, 1999. 